\title{
In Pursuit of Professional Perfectionism
}

\author{
Anda Botezatu, BScN, RN, MN \\ Registered Nurse, Princess Margaret Cancer Centre \\ Toronto, ON
}

"We do not learn from experience...we learn from reflecting on experience."

(Brainy Quote, 2014)

- John Dewey

As an undergraduate student, I continuously strove to improve my nursing knowledge, skills, and clinical practice. In clinical settings, I observed numerous practitioners and registered nurses (RNs) who appeared to perform their jobs in efficient ways, and I often wondered whether one day I might be part of that group of skilled healthcare providers (HCPs). As a student, I had not observed practitioners who were involved in errors and did not have the opportunity to discuss errors with colleagues in the clinical setting. In the academic setting, the topic of errors seemed quite abstract and I believed an error would be something that nursing students would be involved in, but certainly not the skilled practitioners I observed in the clinical setting.

Following personal reflection on the topic of professional perfectionism, I proceeded to examine Brian Goldman's TED speech regarding the impediment that perfectionism may provide to open discussion of errors in the healthcare system (TED Conferences 2011). As stated by Brian Goldman, HCPs may believe that if only we would memorize everything and possess enough knowledge, we would be immune to making errors (TED Conferences 2011). When an error occurs, we might feel isolated and find ourselves examining not only that particular situation but also our competence as practitioners. I am interested in examining whether the lack of discussion of errors by HCPs with nursing students contributes to the perfectionist ideal that learners may develop and continue to strive for in their clinical practice as RNs. 
My focus in this editorial is on the step following the occurrence of an error, that of deciding whether or not to report the error, specifically in the nursing student population. In an effort to focus the discussion in a specific area, I will particularly examine medication errors. As there appears to be a paucity of published studies exploring medication errors in the nursing student population, I would like to begin by focusing on the RN population. RNs involved in medication errors may feel alone, ashamed, and unsupported. Literature suggests that RNs may not report medication errors due to fear of punitive measures, fear of being perceived as incompetent, and a wish to maintain positive collegial relationships (Chenot \& Daniel 2010). The RN involved in a medication error may not wish to selfreport the error due to fear of being perceived as an outsider, or the one who did not possess enough knowledge or experience to avoid such an error. Wishing to maintain positive collegial relationships has been identified as one of the most compelling barriers to the reporting of medication errors (Reid-Searl et al. 2008). RNs may perceive that reporting of medication errors could compromise their image as competent practitioners. Failing to observe the reporting of errors by HCPs may propagate nursing students' perception that competent HCPs are not involved in errors.

What happens when the one involved in a medication error is a nursing student who has not yet observed any HCPs being involved in medication errors, a student striving to attain the perfect skills and knowledge expected of an RN? As an undergraduate nursing student, I was not involved in any medication errors in the clinical setting and I felt proud of myself, believing that competent nursing students were not involved in errors. I later asked myself whether I would have reported a medication error in a setting where it appeared that nobody was involved in errors.

Upon graduation from university I entered the world of nursing, striving to become the perfect RN. After all, according to the perception I had developed, I had been the perfect student, not having been involved in any errors. An event that occurred in the clinical practice was one where I initially did not recognize the deteriorating condition of a patient. After recognizing the patient's declining health status, I enlisted my RN colleagues' assistance and the patient's condition stabilized. In the weeks following the incident, I felt isolated, thinking that I belonged in the category of incompetent RNs, in the category of ones who make mistakes, in sharp contrast to the ones who do not. I often wondered if colleague RNs were ever involved in any errors or if I was the only one. I sought out further information regarding the management of deteriorating patients and believed that if I memorized more and possessed more knowledge I may not be involved in errors in the future. As Brian Goldman states, we believe that if we redouble our efforts to be perfect, we may immunize ourselves against making mistakes again (TED Conferences 2011). 
In the clinical setting, we may want to examine the concept of perfectionism, HCPs' understanding of the characteristics of competent RNs, as well as HCPs' role in providing nursing students with the understanding that competent RNs are sometimes involved in errors. In his speech, Brian Goldman asked listeners to consider the number of errors that a good doctor would make (TED Conferences 2011). I would challenge readers to consider the number of errors that competent RNs make and whether there is a specific standard we are willing to accept. As a nursing student, I would have said that competent nurses were not involved in errors, as I had never witnessed or heard RNs talk about personal or professional errors. Returning to the quote at the beginning of this editorial, I would like to encourage readers to reflect on their experiences with errors in the clinical setting and to openly discuss them with nursing students. Reflection on experiences may allow nursing students to develop accurate perceptions of the skilled HCPs they observe in the clinical setting and encourage students to strive for excellence rather than perfection in their clinical practice.

\section{Acknowledgement}

The author would like to thank Sigma Theta Tau International Lambda Pi-AtLarge for the publication grant awarded.

Correspondence may be directed to: Anda Botezatu, e-mail: Anda.Botezatu@uhn.ca

\section{References}

Brainy Quote. 2014. John Dewey Quotes. Retrieved April 17, 2015. <http:/www.brainyquote.com/ quotes/authors/j/john_dewey.html>.

Chenot, T.M. and L.G. Daniel. 2010. "Frameworks for Patient Safety in the Nursing Curriculum." Journal of Nursing Education 49(10), 559-68. DOI: 10.3928/01484834-20100730-02.

Reid-Searl, K., L. Moxham, S. Walker and B. Happell. 2008. "Shifting Supervision: Implications for Safe Administration of Medication by Nursing Students.” Journal of Clinical Nursing 17(20), 2750 2757. DOI: $10.1111 /$ j.1365-2702.2008.02486.x.

TEDxToronto. 2011. Doctors Make Mistakes. Can We Talk About That? TED Talk Video. Retrieved April 17, 2015.<http://www.ted.com/talks/brian_goldman_doctors_make_mistakes_can_we_talk_ about_that $>$. 